\title{
Poor Nutritional Habits: A Modifiable Predecessor of Chronic Illness? A North Carolina Family Medicine Research Network (NC-FM-RN) Study
}

\author{
Nicole D. Gaskins, Philip D. Sloane, MD, MPH, C. Madeline Mitchell, MURP, \\ Alice Ammerman, DrPH, RD, Scott B. Ickes, and Christianna S. Williams, PhD
}

Purpose: To examine associations between personal nutritional patterns and various indicators of health, disease risk, and chronic illness in a diverse, representative sample of adult patients from primary care settings.

Methods: As part of a survey of adult patients conducted in the waiting rooms of 4 primary care practices in North Carolina (recruitment rate $74.8 \%$ ), a 7-item nutrition screen was administered to 1788 study participants. Other questionnaire items addressed disease and functional status, race/ethnicity, health habits, and demographic factors.

Results: Respondents included 292 African Americans (17.3\%), 1004 non-Hispanic whites (59.4\%), 255 Hispanics (15.1\%), and 126 American Indians (7.4\%); mean age 47.5 years. Thirty percent reported eating 3 or more fast food meals weekly, 29\% drank 3 or more high-sugar beverages weekly, $22 \%$ ate 3 or more high-fat snacks weekly, $36 \%$ ate 3 or more desserts weekly, $11 \%$ reported eating "a lot" of margarine, butter, or meat fat; $62 \%$ ate 2 or fewer fruits or vegetables daily; and $42 \%$ reported consuming protein less than 3 times a week. Scores on a summary measure were worse for prediabetics than for diabetics, for young adults compared with older persons, and for persons reporting good/excellent health versus fair/poor health.

Conclusions: People at high risk for developing chronic illnesses later in life reported poorer diets in comparison with people who are already ill. This probably represents increased nutritional awareness and motivation among people with chronic diseases. Because primary care patients have a high prevalence of chronic disease risk factors, the primary care office setting may constitute a particularly appropriate location for nutrition education. (J Am Board Fam Med 2007;20:124-134.)

Overweight and obesity are major causes of morbidity and mortality in the United States. ${ }^{1,2}$ Annual deaths due to overweight and obesity are estimated to be between 112,000 and $414,000 .^{3-4}$ The $\mathrm{Na}$ -

This article was externally peer reviewed.

Submitted 29 August 2006; revised 28 December 2006; accepted 4 January 2007.

From the School of Medicine (NDG), the Department of Family Medicine (PDS), the Cecil G. Sheps Center for Health Services Research (PDS, CMM, CSW), and the Center for Health Promotion and Disease Prevention (AA, SBI), University of North Carolina, Chapel Hill, NC.

Funding: Supported by Grant R21 HS13521 from the Agency for Healthcare Research and Quality and Grant K07 AG21587 from the National Institute on Aging.

Prior presentation: Portions of this paper were presented at the 2005 Winter Scientific Meeting of the North Carolina Academy of Family Physicians in Asheville, NC. This article is based on a presentation made at the 2006 Agency for Healthcare Research and Quality National Practice-based Research Network Conference, Bethesda, MD, May 15-17, 2006.

Conflict of interest: none declared.

Corresponding author: Philip D. Sloane, MD, MPH, Department of Family Medicine, University of North Carolina at Chapel Hill, 725 Martin Luther King Jr. Blvd., CB 7595 Aycock Building, Chapel Hill, NC 27599-7590 (E-mail: psloane@med.unc.edu). tional Health and Nutrition Examination Survey (1999-2000) indicated that nearly two thirds of US adults are overweight (body mass index $[\mathrm{BMI}] \geq 25$ ) and nearly one third are obese (BMI $\geq 30)$. The prevalence of overweight and obesity in minorities, especially minority women, is generally higher than that of whites in the United States. ${ }^{5,6}$

Excess weight is an important risk factor for chronic illness, including type 2 diabetes. Nearly $70 \%$ to $80 \%$ of type 2 diabetic patients are either overweight or obese. ${ }^{7,8}$ The prevalence and incidence of both obesity and diabetes have steadily increased in the United States in both genders, all ages, all educational levels, and all smoking levels over the past several years. ${ }^{9}$ Diabetes prevalence varies by ethnic group; diabetes prevalence in whites is $8.7 \%$, whereas Hispanics, African Americans, and American Indians have prevalences that are $1.7,1.8$, and 2.2 times greater, respectively. ${ }^{2}$ Data from 2005 estimated the prevalence of diabetes in the United States to be 20.8 million people, or $7.0 \%$ of the population. ${ }^{2}$ An additional 20 mil- 
lion have prediabetes, a strong risk factor for developing diabetes later in life. ${ }^{7}$ The cost of diabetes in the United States is enormous; direct and indirect costs were estimated at $\$ 132$ billion in 2002. ${ }^{2}$ Extensive risks are associated with long-term type 2 diabetes, especially with prolonged diagnosis. For instance, by the time many patients are diagnosed, vascular damage has already occurred. Therefore, preventing the disease or delaying its onset provide the best approaches to reducing diabetes complications. ${ }^{10}$

Diet can influence the development of type 2 diabetes; recent epidemiologic studies have shown that a low-fiber diet, high trans-fatty acid intake, low unsaturated-to-saturated fat intake ratio, and the absence of or excess alcohol consumption to be associated with an increased risk of type 2 diabetes. ${ }^{11}$ Lifestyle interventions have been successful in addressing type 2 diabetes. For example, the Diabetes Prevention Program demonstrated that the 2-year incidence of diabetes in high-risk persons could be decreased $58 \%$ by adherence to a lifestyle intervention which included a diet based on the Food Guide Pyramid and regular, moderate physical activity. ${ }^{12}$

Primary care settings have great potential as sites for lifestyle-related chronic disease prevention and management. ${ }^{13-15}$ Developing successful assessment methods and management approaches to address nutrition-related disease in these settings is, therefore, a high priority. ${ }^{16}$ To develop such interventions, primary care physicians need to understand the factors that influence the dietary habits of their patients and how these factors vary across patient populations. This study used an established diet screening instrument to assess the habits of a diverse sample of 1788 primary care patients and factors associated with them.

\section{Methods}

This project was conducted under the auspices of the North Carolina Family Medicine Research Network (NC-FM-RN), a statewide network of 24 family practices. ${ }^{17}$ As part of a broader survey of patients from 4 newly recruited network practices, a 7-item nutrition habit screen designed for use in primary care settings by AA and colleagues was used to assess the diet of a representative sample of adult patients from these practices. The instrument's items, adapted from a longer, validated in- strument, inquire about fast food, sugar-containing beverages, high-fat snacks, desserts or sweets, fat, fruits and vegetables, and protein; all items are scored on a 3 -point scale with 0 representing the most healthy behavior and 2 representing the least healthy behavior. ${ }^{16,18,19}$ Using these items, a total nutrition score was generated by summing the scores from the 7 items, yielding a scale with a possible range between 0 (best dietary habits) to 14 (poorest dietary habits). If 1 or 2 of the 7 items are missing, the case-wise average of the nonmissing items is imputed so that the total score maintains the same range; if more than 2 items are missing, the summary score is not computed. The 7-question screen has been validated by comparing it to the Dietary Risk Assessment, a widely used food frequency questionnaire, ${ }^{19,20}$ in 68 communitydwelling adults; the Pearson correlation coefficient between the 2 instruments was $r=0.67(P<$ $.0001)$, indicating that the measures were highly correlated. $^{21}$

The study's data collection questionnaire also included information on the respondents' demographic status, BMI, medical history (including diagnoses such as diabetes and hypertension), smoking status, physical activity, and alcohol intake. In addition, persons at high risk for diabetes were identified using the American Diabetes Association (ADA) Diabetes Risk Screen. ${ }^{22,23}$ The project was approved by the Institutional Review Board of the School of Medicine of the University of North Carolina at Chapel Hill.

We administered the questionnaire to 1788 consecutive adult patients who presented for a visit to a medical provider (physician, nurse practitioner, or physician assistant) in 4 family practice offices in North Carolina. Three were private practices in small- or medium-sized towns, and the fourth was a rural community health center; the 4 practices were chosen because their joint patient populations represented a diversity of racial and ethnic groups. As described previously, ${ }^{17}$ the network surveyed patients in a practice by placing 1 or 2 trained research assistants in the waiting rooms of each practice for 20 days. Research assistants approached eligible people about participation in the survey, obtained written consent, assisted with survey completion, and gathered completed surveys. Eligibility criteria included a minimum age of 18 years, an appointment on the day of recruitment, absence of acute distress, and ability to compre- 
hend the consent form. Both English and Spanish versions of the consent form and questionnaire were available, and bilingual research assistants were placed in practices with high numbers of Hispanic patients. The overall recruitment rate was $74.8 \%$ of eligible patients. These analyses report on the 1714 people ( $95.9 \%$ of respondents) for whom responses were provided to the majority of the nutrition items.

BMI was calculated as reported weight in kilograms divided by the square of the reported height in meters. Nutrition scores for each respondent were calculated as noted previously. A high-quality diet was defined as one rich in protein, fruits, and vegetables and low in saturated fats, sweets, and fast foods. ${ }^{17-19}$ Respondents were defined as at "high risk" for diabetes if they scored 10 or higher on the ADA Diabetes Risk Screen and did not report a diagnosis of diabetes.

All descriptive and hypothesis-testing analyses were completed using SAS software. ${ }^{24}$ Simple descriptive statistics were used to describe the sample and the distribution of each item in the nutritional habit score. To evaluate the internal consistency of the nutritional habit score, interitems correlations, item-total correlations, and Cronbach $\alpha$ were computed. We also evaluated the distribution of the nutritional habit score for normality by visual inspection of the frequency distribution and Q-Q plots. These assessments indicated that the assumption of a normal distribution was valid, justifying the use of parametric statistical methods. To compare the mean nutritional habit scores across selected patient characteristics, we used analysis of variance, first adjusting only for clinic location. To identify characteristics independently associated with the nutritional habit score, we then estimated a multiple linear regression model, including all characteristics from the bivariate analyses with the exception of BMI. BMI was dropped because it had no association with the nutritional habit score in the bivariate (or multivariable) analyses, and it had a substantial amount of missing data (11.4\%). To examine the association between race/ethnicity and each nutritional habit item, binary logistic regression models were estimated for selected items (dichotomized as 3 or more servings vs $0-2$ within the specified interval), adjusting for practice location, age, gender, smoking status, alcohol consumption, physical activity, BMI, and self-reported health status. We similarly tested the difference between diabetics and nondiabetics at high risk for the disease with respect to the nutritional habit items, using logistic regression, and adjusting for practice location, age, gender, race/ethnicity, smoking status, alcohol consumption, and physical activity.

\section{Results}

Table 1 displays the distribution of selected demographic and health status variables in the study sample. Respondents were racially and ethnically diverse, including 275 African Americans (16.8\%), 982 non-Hispanic whites (60.1\%), 242 Hispanics (14.8\%), and 124 American Indians (7.6\%); the mean age was 47.4 years. The mean BMI was 29.6, indicating that the average respondent was overweight and nearly obese. Nearly one half (41.6\%) reported having high blood pressure; one third (32.4\%) reported depression; and $17.5 \%$ reported having diabetes. Application of the ADA Diabetes Risk Screen indicated that an additional $40 \%$ were at high risk for developing diabetes.

Scores on the nutrition screening questionnaire are displayed in Table 2. Nearly one third of respondents reported eating fast food meals at least 3 times a week. Sweet drinks were consumed 3 or more times daily, and desserts were consumed 3 or more times a week by $29 \%$ and $38 \%$ of respondents, respectively. Fewer than one-third of respondents reported eating 3 or more servings of fruits and vegetables daily, and nearly one half reported fewer than 3 high-protein meals per week. The average overall nutritional habit score was 6.01 $(\mathrm{SD}=2.73)$.

When nutrition scores were examined by race/ ethnicity, Hispanics had significantly better overall scores because of lower intake of fast foods, sugared drinks, desserts, and high-fat snacks than other groups. African Americans reported the highest consumption of high-fat snacks; American Indians the highest consumption of sugared drinks and desserts and the lowest consumption of protein; and non-Hispanic whites the highest consumption of fast-food meals and desserts. Tables 3 and 4 and Figure 1 display these results.

When nutrition score was examined by health status in bivariate comparisons (Table 3), males, younger respondents, smokers, and alcoholic beverage drinkers had significantly higher mean nutrition scores, and therefore poorer quality diets, compared with their female, older, nonsmoking, 


\begin{tabular}{|c|c|c|c|c|c|}
\hline & Number & Percentage & Mean & SD & Range \\
\hline Age (years) & & & 47.4 & 16.9 & $18.0,94.9$ \\
\hline \multicolumn{6}{|l|}{ Gender } \\
\hline Male & 604 & 35.3 & & & \\
\hline Female & 1107 & 64.7 & & & \\
\hline \multicolumn{6}{|l|}{ Education } \\
\hline 8th grade or less & 200 & 11.8 & & & \\
\hline High school, no diploma & 205 & 12.1 & & & \\
\hline High school graduate or GED & 506 & 30.0 & & & \\
\hline Some college, no degree & 387 & 22.9 & & & \\
\hline Associate's degree & 144 & 8.5 & & & \\
\hline Bachelor's degree & 151 & 8.9 & & & \\
\hline Postgraduate school or degree & 95 & 5.6 & & & \\
\hline Married/living with partner & 1052 & 62.8 & & & \\
\hline \multicolumn{6}{|l|}{ Race/ethnicity } \\
\hline African American & 275 & 16.8 & & & \\
\hline White, non-Hispanic & 982 & 60.1 & & & \\
\hline American Indian & 124 & 7.6 & & & \\
\hline Hispanic/Latino & 242 & 14.8 & & & \\
\hline Other & 12 & 0.7 & & & \\
\hline \multicolumn{6}{|l|}{ Practice location } \\
\hline A & 441 & 25.7 & & & \\
\hline $\mathrm{B}$ & 390 & 22.8 & & & \\
\hline $\mathrm{C}$ & 621 & 36.2 & & & \\
\hline $\mathrm{D}$ & 262 & 15.3 & & & \\
\hline \multicolumn{6}{|l|}{ Current health problems } \\
\hline Heart disease & 210 & 12.7 & & & \\
\hline High blood pressure & 700 & 41.6 & & & \\
\hline Lung disease & 97 & 5.9 & & & \\
\hline Stroke or mini-stroke & 72 & 4.4 & & & \\
\hline Depression & 538 & 32.4 & & & \\
\hline Chronic back pain & 478 & 28.8 & & & \\
\hline Cancer & 76 & 4.6 & & & \\
\hline Diabetes & 291 & 17.5 & & & \\
\hline Osteoarthritis & 237 & 14.4 & & & \\
\hline Rheumatoid arthritis & 150 & 9.1 & & & \\
\hline Fibromyalgia & 105 & 6.4 & & & \\
\hline \multicolumn{6}{|l|}{ Self-reported health } \\
\hline Excellent & 142 & 8.3 & & & \\
\hline Very good & 392 & 23.0 & & & \\
\hline Good & 575 & 33.7 & & & \\
\hline Fair & 458 & 26.8 & & & \\
\hline Poor & 140 & 8.2 & & & \\
\hline Drinks alcohol & 536 & 31.7 & & & \\
\hline Engaged in physical activity in past week & 981 & 59.5 & & & \\
\hline Physically active 5 days/week, $>30$ minutes/day & 642 & 39.0 & & & \\
\hline Current smoker & 401 & 23.6 & & & \\
\hline Body mass index (BMI) & & & 29.6 & 7.1 & $15.0,64.6$ \\
\hline Normal or underweight (BMI <25) & $414 \dagger$ & 27.3 & & & \\
\hline Overweight (BMI 25-30) & 484 & 31.9 & & & \\
\hline Obese $(\mathrm{BMI}>30)$ & 621 & 40.9 & & & \\
\hline
\end{tabular}

* The sample $\mathrm{N}$ includes all those who answered the nutritional habit questions. The sample size for individual characteristics varies from 1519 to 1711 because of missing data.

† Includes 30 people classified as underweight $(\mathrm{BMI}<18.5)$. 


\begin{tabular}{|c|c|c|}
\hline $\begin{array}{l}\text { Item and Response Choices from Nutritional Habits } \\
\text { Survey }\end{array}$ & Number & Percentage \\
\hline $\begin{array}{l}\text { Number of times fast food eaten per week } \\
0\end{array}$ & 239 & 14.6 \\
\hline 1 to 2 & 877 & 53.4 \\
\hline 3 or more & 526 & 32.0 \\
\hline $\begin{array}{l}\text { Number of glasses of soda or sweet tea consumed per day } \\
0\end{array}$ & 549 & 32.7 \\
\hline 1 to 2 & 639 & 38.0 \\
\hline 3 or more & 492 & 29.3 \\
\hline $\begin{array}{l}\text { Number of times high-fat snacks consumed per week } \\
0 \text { to } 1\end{array}$ & 836 & 50.4 \\
\hline 2 & 438 & 26.4 \\
\hline 3 or more & 386 & 23.3 \\
\hline $\begin{array}{l}\text { Number of times desserts or sweets consumed per week } \\
0 \text { to } 1\end{array}$ & 610 & 36.4 \\
\hline 2 & 433 & 25.9 \\
\hline 3 or more & 631 & 37.7 \\
\hline $\begin{array}{l}\text { Amount of margarine, butter, meat fat consumed } \\
\text { None or very little }\end{array}$ & 729 & 42.7 \\
\hline Some & 787 & 46.1 \\
\hline A lot & 192 & 11.2 \\
\hline $\begin{array}{l}\text { Number of servings of fruits or vegetables eaten per day } \\
3 \text { or more }\end{array}$ & 568 & 34.4 \\
\hline 2 & 562 & 34.1 \\
\hline 1 or less & 519 & 31.5 \\
\hline $\begin{array}{l}\text { Number of times lean protein eaten per week } \\
3 \text { or more }\end{array}$ & 947 & 56.5 \\
\hline 1 to 2 & 674 & 40.2 \\
\hline 0 & 55 & 3.3 \\
\hline Overall Nutritional Habit Score (0-14), Mean (SD)† & 6.01 & $(2.73)$ \\
\hline
\end{tabular}

* The sample $\mathrm{N}$ includes all those who answered at least 5 of the 7 nutritional habit questions. The sample size for individual items varies from 1642 to 1708 because of missing data.

+ Scored as the sum of the 7 items, each 0 to 2, with higher scores reflecting poorer nutritional habits. If 2 or fewer items were missing, values for missing items were imputed as the mean of the nonmissing items. Cronbach's $\alpha$ for the score is 0.558 , and item total correlation range from 0.069 (lean protein consumption) to 0.407 (high-fat snack consumption). The median value is 6 , and the most common (modal) value is 7.0, indicating very little skew. Visual inspection of the distribution and Q-Q plot indicate that the assumption of a normal distribution (and the application of parametric statistical tests) is valid.

nondrinking counterparts. Reported levels of physical activity, self-reported health, and BMI were not significantly associated with nutrition score. Multiple linear regression confirmed these results (Table 4), except that in these analyses the relationship between alcohol intake and nutrition score was reduced to borderline statistical significance $(P=$ $.106)$, and physical activity had a stronger although still not statistically significant $(P=.097)$ association with better nutritional habits.

Both high- and low-risk nondiabetics had poorer nutritional scores than diabetics (Table 3). When nondiabetics at high risk of developing diabetes were compared with diagnosed diabetics, their poorer nutrition scores were seen to be largely due to higher rates of intake of sugared drinks and desserts and lower rates of consumption of fruits and vegetables (Figure 2).

\section{Discussion}

Nutrition has a major and well-documented impact on health and chronic illnesses. Healthy eating habits such as consumption of fruits and vegetables, ${ }^{25-28}$ lean protein sources, adequate fiber, ${ }^{29}$ and foods with a low glycemic index and saturated fat content have been implicated in weight loss, in improved prevention and survivorship after chronic illness, and in promoting healthy blood cholesterol, blood pressure, ${ }^{30}$ blood lipids, ${ }^{31,32}$ and glycemic control. ${ }^{12,33}$ Likewise, unhealthy dietary behaviors have been associated with numerous negative 
Table 3. Relationship between Nutritional Habit Score and Selected Demographic and Health Status Variables

$(\mathrm{N}=\mathbf{1 7 1 4})$

\begin{tabular}{|c|c|c|c|}
\hline \multirow[b]{2}{*}{ Variable } & \multicolumn{2}{|c|}{ Nutritional Habit Score } & \multirow[b]{2}{*}{$P$ Value* } \\
\hline & Mean & SD & \\
\hline \multicolumn{4}{|l|}{ Race/ethnicity } \\
\hline African American & 6.27 & 2.79 & .297 \\
\hline American Indian & 6.57 & 2.56 & .759 \\
\hline Hispanic/Latino & 5.10 & 2.45 & $<.001$ \\
\hline Other & 5.62 & 2.13 & .285 \\
\hline White, non-Hispanic & 6.12 & 2.79 & - \\
\hline \multicolumn{4}{|l|}{ Diabetes/pre-diabetes } \\
\hline Not diabetic and low risk & 6.12 & 2.74 & $<.001$ \\
\hline Not diabetic and high risk & 6.43 & 2.68 & $<.001$ \\
\hline Diabetic & 5.06 & 2.64 & $-\dagger$ \\
\hline \multicolumn{4}{|l|}{ Sex } \\
\hline Male & 6.36 & 2.65 & $<.001$ \\
\hline Female & 5.82 & 2.75 & - \\
\hline \multicolumn{4}{|l|}{ Age } \\
\hline 18 to 44 years old & 6.42 & 2.76 & $<.001$ \\
\hline $45+$ years old & 5.67 & 2.67 & \\
\hline \multicolumn{4}{|l|}{ Smoking status } \\
\hline Nonsmoker & 5.73 & 2.68 & $<.001$ \\
\hline Smoker & 6.91 & 2.70 & - \\
\hline \multicolumn{4}{|l|}{ Alcohol consumption } \\
\hline Do not drink alcohol & 5.87 & 2.68 & .002 \\
\hline Drink alcohol & 6.32 & 2.81 & - \\
\hline \multicolumn{4}{|c|}{ Physically active 5 days/week, $>30$ minutes/day } \\
\hline No & 6.09 & 2.65 & .350 \\
\hline Yes & 5.94 & 2.85 & - \\
\hline \multicolumn{4}{|l|}{ Self-reported health status } \\
\hline Fair/poor & 5.91 & 2.57 & .493 \\
\hline Good/very good/excellent & 6.07 & 2.81 & - \\
\hline \multicolumn{4}{|l|}{ BMI } \\
\hline Normal or underweight & 5.99 & 2.90 & .632 \\
\hline Overweight & 6.25 & 2.69 & .431 \\
\hline Obese & 6.11 & 2.68 & 一‡ \\
\hline
\end{tabular}

* Based on ANOVA with nutritional habit score as the dependent variable and the specified demographic or health status characteristic as the independent variable and adjusting for practice location.

$\dagger P$ value for comparison of low risk versus high risk among nondiabetics is .097 .

$\ddagger P$ value for comparison of normal/underweight versus overweight is 0.243 .

health outcomes and chronic diseases, including hypertension, insulin resistance and type 2 diabetes, obesity, cardiovascular disease, osteoporosis, and several cancers.

Persons with chronic illness and risk factors for chronic disease tend to be concentrated in the everyday office practices of family physicians and other primary care specialists. ${ }^{17}$ The study respondents described in this paper, a random sample of adults from 4 family practice settings in
North Carolina that serve a wide range of ethnic and racial groups, had high levels of disease risk and chronic disease. Forty percent engaged in no regular physical activity; 24\% were current smokers; $18 \%$ had diabetes; $42 \%$ had hypertension; and $13 \%$ had a history of heart disease. Of particular note is the high prevalence of obesity in these people $(41 \%)$ and the fact that more than a third (40\%) scored "high risk" on the ADA Diabetes Risk Screen. ${ }^{20,21}$ Obesity has been 
Table 4. Multiple Linear Regression for Nutritional Habit Score ( $\mathrm{N}=1424)$

\begin{tabular}{|c|c|c|c|}
\hline Variable & Estimate & SE & $P$ Value \\
\hline Intercept & 7.682 & 0.329 & $<.001$ \\
\hline Race/ethnicity & & & $<.001^{*}$ \\
\hline African American & 0.363 & 0.198 & .067 \\
\hline American Indian & -0.109 & 0.342 & .750 \\
\hline Hispanic/Latino & -1.284 & 0.273 & $<.001$ \\
\hline Other & -0.726 & 0.892 & .416 \\
\hline White, non-Hispanic & reference & & \\
\hline Diabetes/prediabetes & & & $<.001 \dagger$ \\
\hline Not diabetic, low risk & 0.538 & 0.215 & .013 \\
\hline Not diabetic, high risk & 1.164 & 0.199 & $<.001$ \\
\hline Diabetic & reference & & \\
\hline Male gender & 0.571 & 0.148 & .001 \\
\hline Age (per year) & -0.041 & 0.005 & $<.001$ \\
\hline Practice location & & & $.003 \neq$ \\
\hline A & 0.300 & 0.205 & .143 \\
\hline $\mathrm{B}$ & -0.257 & 0.215 & .232 \\
\hline $\mathrm{C}$ & 0.628 & 0.283 & .027 \\
\hline $\mathrm{D}$ & reference & & \\
\hline Smoker & 0.834 & 0.168 & $<.001$ \\
\hline Drinks alcohol & -0.262 & 0.162 & .106 \\
\hline Physically active 5 days/week, $>30$ minutes/day & -0.245 & 0.147 & .097 \\
\hline Self-reported health status as very good or excellent & -0.102 & 0.159 & .521 \\
\hline
\end{tabular}

* Overall type $3 P$ value for race/ethnicity (4 df); additional pairwise comparisons in which $P<.05$ include African American versus Hispanic/Latino $(P<.001)$ and American Indian versus Hispanic/Latino $(P=.005)$.

† Overall type $3 P$ value for diabetes status $(2 \mathrm{df}) ; P$ value for pairwise comparison of high and low risk nondiabetics is $<0.001$.

‡ Overall type $3 P$ value for clinic location $(3 \mathrm{df})$. Pairwise comparisons that are significant at $P<.05$ include A versus $\mathrm{B}(P=.004)$ and $\mathrm{B}$ versus $\mathrm{C}(P<.002)$.

strongly linked with the likelihood of developing diabetes and other chronic illnesses, ${ }^{7,8}$ and these 2 patient groups might particularly benefit from interventions aimed at preventing the development and complications of lifestyle-related chronic illness.

The results of this study suggest several ways in which nutritional interventions may target subgroups of primary care patients. As is shown in Tables 3 and 4 , younger age and better self-reported health are associated with poorer nutrition scores. Although this does not suggest that the lifestyle habits of patients with existing chronic illness can be ignored by primary care providers, it seems that patients at known risk for chronic illness, such as persons with prediabetes, may be particularly appropriate targets for nutrition-related screening and services.

We were not surprised to find that the reported nutritional habits of known diabetics were better than those of prediabetics (Figure 2). Of course, it is possible that people with the disease reported healthier habits because they know the "right answers"; however, a more likely explanation is that diabetics, by virtue of the education that is part of health care for that diagnosis, understand the advantages of healthier eating. They have, therefore, made changes to improve their diet in response to the disease state. On the other hand, patients at high risk of developing diabetes, some of whom no doubt already have the (undiagnosed) disease, may not have the same sense of urgency to improve their diet as do known diabetics. Thus, it would seem that intense clinical and public health efforts, if targeted at people who were at high risk of developing disease and disability, might help forestall the development of these diseases and their complications.

As family medicine moves toward identifying practice models that focus more on chronic disease care and prevention, the role of the family medicine office in promoting nutritional health, physical activity, and other healthy habits may well increase. In this context, identification and management of 


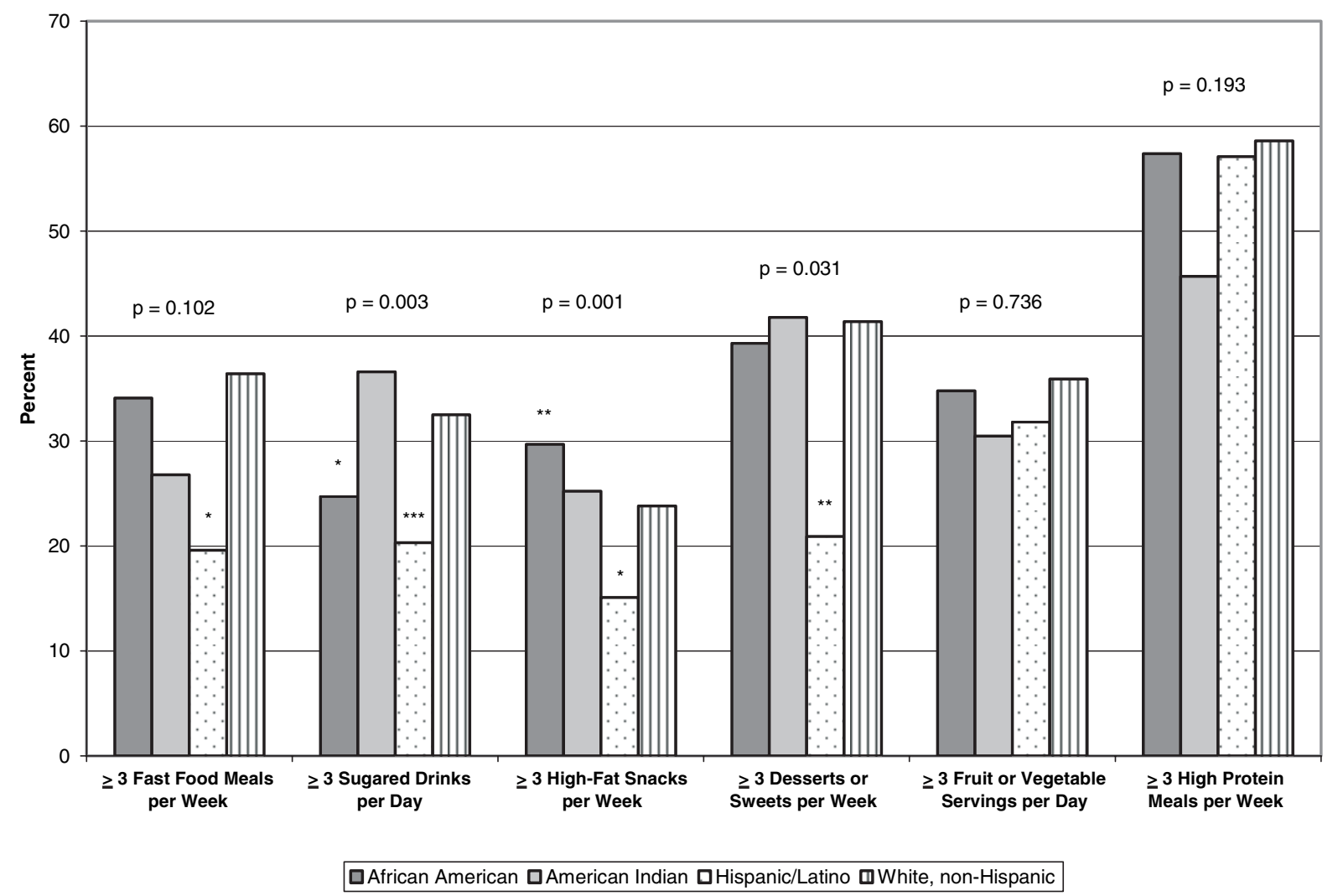

Figure 1. Racial and ethnic differences in the percentage of respondents reporting selected nutritional habits. $P$ values are based on logistic regression models with given food habit as the dependent variable and race/ethnicity as the independent variable, adjusted for clinic site, age, sex, smoking status, alcohol consumption, physical activity, self-rated health, and BMI. $\mathrm{N}$ ranges from 1323 to 1357 , depending on missing data for the food habit. Percentages are not adjusted. $*, P<.05 ; * *, P<.01$; and $* * *, P<.001$ for comparison with white, nonHispanic respondents.

high-risk patients may become an increasingly important aspect of primary care. Examples of such target groups might include persons who have prediabetes or people making the transition from adolescence to early adulthood. ${ }^{34,35}$

The benefits of primary prevention, including maintaining an optimum body weight, eating a healthy diet, exercising, and not smoking, in prevention of chronic illness have been known for many years. With the increased time and financial constraints in today's primary care practice, one of the challenges is choosing which populations to target to maximize the impact of efforts aimed at reducing chronic disease risk. These data suggest that the primary care office may be an ideal setting to carry out this case identification and, perhaps, also the subsequent efforts at risk reduction. Thus, screening for chronic disease risk, coupled with a short screen for nutritional habits, initial counsel- ing, and links with existing community resources may be worth testing.

Of particular importance is the translation of intensive interventions like the Diabetes Prevention Program into more practical approaches that can be feasibly implemented in a practice setting. ${ }^{12}$ Currently, a series of primary care-based studies are exploring this question, under funding from the Robert Wood Johnson Foundation Prescription for Health initiative. ${ }^{36}$ By building on the increased knowledge about behavior change that has developed in the community and public health areas over recent decades, they will hopefully provide new insights into feasible methods by which primary care practices can help prevent nutrition-related chronic illness.

This research study was conducted by the North Carolina Family Medicine Research Network (NC-FM-RN). The NC- 


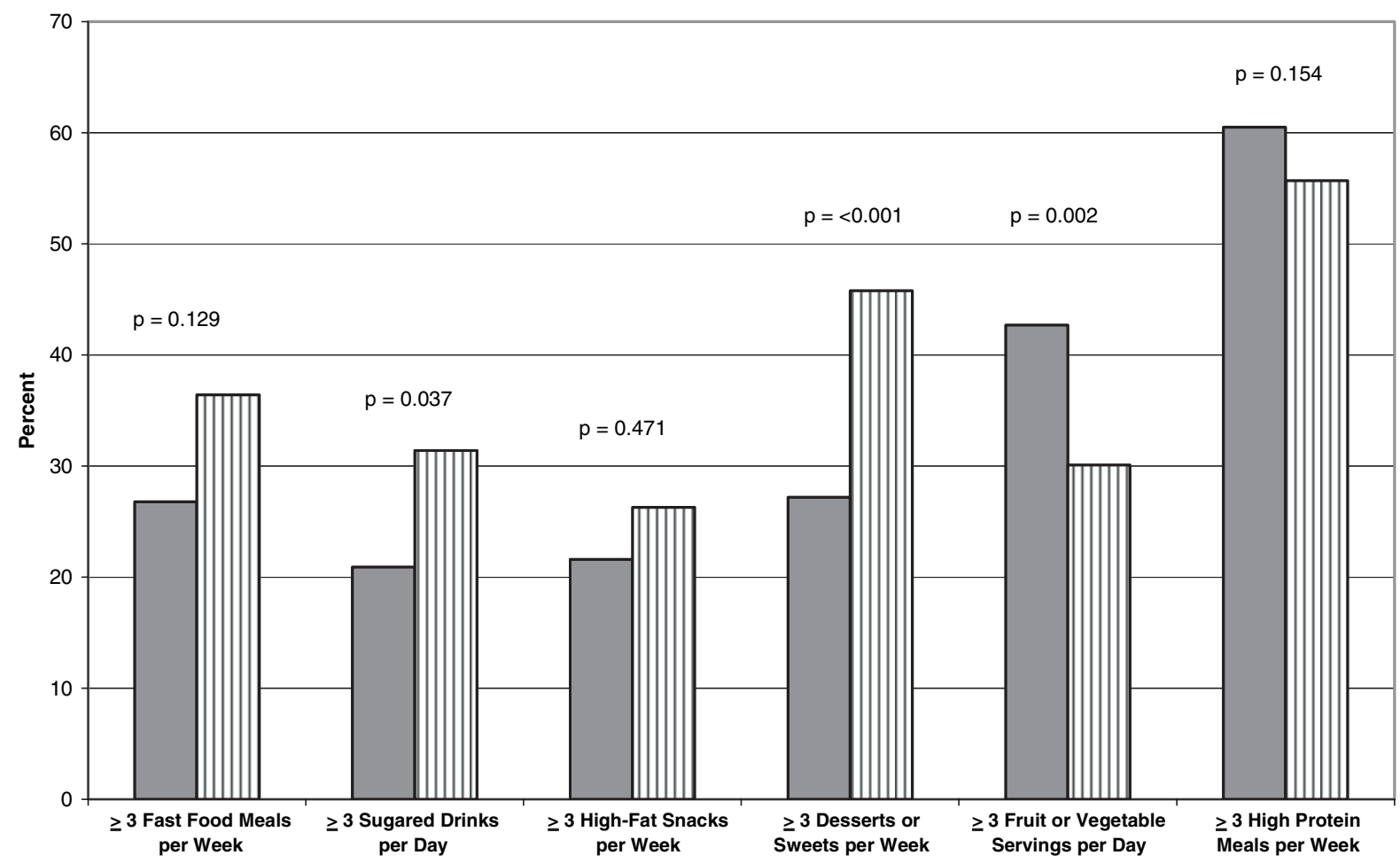

口Known diabetic $\mathbf{D H i g h}$ risk, non-diabetic

Figure 2. Comparison of selected nutritional habits of diabetics with those of nondiabetics who are at high risk for the disease. $P$ values are based on logistic regression models with given food habit as the dependent variable and diabetes group as the independent variable, adjusted for clinic site, age, sex, race, smoking status, alcohol consumption, and physical activity. $\mathrm{N}$ ranges from 801 to 822, depending on missing data for the food habit. Percentages are unadjusted.

FM-RN is jointly sponsored by the Department of Family Medicine, the Thurston Arthritis Research Center, and the Cecil G. Sheps Center for Health Services Research at the University of North Carolina at Chapel Hill (UNC-CH), in collaboration with the North Carolina Academy of Family Physicians. The project codirectors are Leigh Callahan, $\mathrm{PhD}$, and Philip Sloane, MD, MPH. Participating family practices have included: Biddle Point Health Center, Charlotte; Bladen Medical Associates, Elizabethtown; Black River Health Services, Atkinson and Burgaw; Blair Family Medicine, Wallace; Chatham Primary Care, Siler City; Community Family Practice, Asheville; Cornerstone Medical Center, Burlington; Crissman Family Practice, Graham; Dayspring Family Medicine, Eden; Goldsboro Family Physicians, Goldsboro; Henderson Family Health Center, Hendersonville; Lumber River Family Practice, Lumberton; Moncure Community Health Center, Moncure; North Park Medical Center, Charlotte; Orange Family Medical Center, Hillsborough (pilot site); Person Family Medical Center, Roxboro; Pittsboro Family Medicine, Pittsboro; Prospect Hill Community Health Center, Prospect Hill; Robbins Family Practice, Robbins; South Cabarrus Family Physicians, Harrisburg, Concord, Mt. Pleasant, and Kannapolis; Summerfield Family Practice, Summerfield; and Village Family Medicine, Chapel Hill. Activities of the NC-FP-RN have been supported by the Centers for Disease Control and Prevention, the Agency for Healthcare Research and Quality, the National
Institutes of Health, the Department of Family Medicine at UNC-CH, and the Program on Health Outcomes at UNC$\mathrm{CH}$. In addition, the study would like to acknowledge the work of Ana Cerna, Nicole Collins, Samantha Earnhardt, Laura Hinson, Karishma Patel, William Bradford, and Julia Thorp, each of whom made significant contributions to the data collection process.

\section{References}

1. Must A, Spadano J, Coakley EH, Field AE, Colditz G, Dietz WH. The disease burden associated with overweight and obesity. JAMA 1999;282:1523-29.

2. Centers for Disease Control and Prevention. National Diabetes Fact Sheet: General Information and National Estimates on Diabetes in the United States, 2000. Atlanta, GA: United States Department of Health and Human Services, Centers for Disease Control and Prevention; 2002.

3. Flegal KM, Graubard BI, Williamson DF, Gail MH. Excess deaths associated with underweight, overweight, and obesity. JAMA 2005;293:1861-67.

4. Mokdad AH, Marks JS, Stroup DF, Gerberding JL. Actual causes of death in the United States, 2000. 
JAMA 2004;291:1238-45. Erratum in: JAMA 2005; 293:293-4.

5. Robert SA, Reither EN. A multilevel analysis of race, community disadvantage, and body mass index among adults in the US. Soc Sci Med 2004;59:242134.

6. Flegal KM, Carroll MD, Ogden CL, Johnson CL. Prevalence and trends in obesity among US adults, 1999-2000. JAMA 2002;288:1723-27.

7. National Institute of Diabetes and Digestive and Kidney Diseases. Diabetes Prevention Program Meeting Summary; 2001 Aug; Diabetes Mellitus Interagency Coordinating Committee.

8. Resnick HE, Valsania P, Halter JB, Lin X. Relation of weight gain and weight loss on subsequent diabetes risk in overweight adults. J Epidemiol Community Health 2000;54:596-602.

9. Mokdad 0AH, Ford ES, Bowman BA, et al. Prevalence of obesity, diabetes, and obesity-related health risk factors, 2001. JAMA 2003;289(1):76-9.

10. American Diabetes Association and National Institute of Diabetes, Digestive and Kidney Diseases. Position statement: the prevention or delay of type 2 diabetes. Diabetes Care 2002;25:742-49.

11. Parillo M, Riccardi G. Diet composition and the risk of type 2 diabetes: epidemiological and clinical evidence. Br J Nutr 2004;92(1):7-19.

12. Diabetes Prevention Program Research Group. Reduction in the incidence of type 2 diabetes with lifestyle intervention or Metformin. N Engl J Med 2002;346:393-403.

13. Pignone MP, Ammerman A, Fernandez L, Orleans CT, Pender N. Counseling to promote a healthy diet in adults. A summary of the evidence for the U.S. Preventive Services Task Force. Am J Prev Med 2003;24(1):75-92.

14. Graham L, Sketris I, Burge F, Edwards L. The effect of a primary care intervention on management of patients with diabetes and hypertension: a pre-post intervention chart audit. Healthc Q 2006; 9(2):62-71.

15. Stern E, Benbassat CA, Goldfracht M. Impact of a two-arm educational program for improving diabetes care in primary care centres. Int J Clin Pract 2005;59(10):1126-30.

16. Glasgow RE, Ory MG, Klesges LM, Cifuentes M, Fernald DH, Green LA. Practical and relevant selfreport measures of patient health behaviors for primary care research. Ann Fam Med 2005;3(1):73-81.

17. Sloane PD, Callahan L, Kahwati L, Mitchell CM. Development of a practice-based patient cohort for primary care research. Fam Med 2006;38:50-7.

18. North Carolina Department of Health and Human Services. Physical activity and nutrition behaviors monitoring form. [cited 2006 June 20]. Available from: http://www.eatsmartmovemorenc.com/data/ PAN\%20Behaviors\%20Monitoring\%20Form.pdf.

19. Ammerman A, Haines P, DeVellis R, et al. A brief dietary assessment to guide cholesterol reduction in low income individuals: design and validation. J Amer Diet Assoc 1991;91:1385-90.

20. Cheng C, Graziana C, Diamond JJ. Validation of the dietary risk assessment food frequency questionnaire against the Keys score for saturated fat and cholesterol. J Nutr Educ Behav 2005;37:152-3.

21. Jilcott SB, Keyserling TC, Samuel-Hodge CD, Johnston LF, Gross MD, Ammerman AS. Validation of a brief dietary assessment to guide counseling for cardiovascular disease reduction in the underserved population. J Am Diet Assoc. 2007:107(2):246-55.

22. American Diabetes Association [homepage on the Internet]. Risk Screen for Diabetes. [cited 2006 Jun 20]. Available from: http://www.diabetes.org/risktest.jsp.

23. Herman WH, Smith PJ, Thompson TJ, Engelgau MM, Aubert RE. A new and simple questionnaire to identify people at increased risk for undiagnosed diabetes. Diabetes Care 1998;21:1029-31.

24. SAS Release 8.02. Cary (NJ): SAS Institute.

25. United States Department of Agriculture (USDA), United States Department of Health and Human Services. Nutrition and your health: dietary guidelines for Americans. 3rd ed. USDA home and garden bulletin no. 232. Washington (DC): US Government Printing Office; 2000.

26. Byers $T$. The role of nutrition and nutrients in the prevention of chronic diseases. Prim Care 2002;29: 615-27.

27. Swinburn BA, Caterson I, Seidell JC, James WP. Diet, nutrition and the prevention of excess weight gain and obesity. Public Health Nutr 2004;7:123-46.

28. Srinath Reddy K, Katan MB. Diet, nutrition and the prevention of hypertension and cardiovascular diseases. Public Health Nutr 2004;7:167-86.

29. Glade MJ. Food, nutrition, and the prevention of cancer: a global perspective. American Institute for Cancer Research/World Cancer Research Fund, American Institute for Cancer Research, 1997. Nutrition 1999;15:523-6.

30. Appel LJ, Moore TJ, Obarzanek E, et al. A clinical trial of the effects of dietary patterns on blood pressure. N Engl J Med 1997;336:1117-24.

31. Blankenhorn DH, Johnson RL, Mack WJ, El Zein HA, Vailas LI. The influence of diet on the appearance of new lesions inhuman coronary arteries. JAMA 1990;263:1646-52.

32. Arntzenius AC, Kromhout JD, Barth JD, et al. Diet, lipoproteins, and the progression of coronary artherosclerosis: the Leiden intervention trial. $\mathrm{N}$ Engl J Med 1985;312:805-11. 
33. Wing R, Marcus M, Blair EH, Watanabe R, Bonomi $\mathrm{P}$, Bergman RN. Caloric restriction per se is a significant factor in improvements in glycermic control and insulin sensitivity during weight loss in obese NIDDM patients. Diabetes Care 1994;17:30-6.

34. Demory-Luce D, Morales M, Nicklas T, Baranowski T, Zakeri I, Berenson G. Changes in food group consumption patterns from childhood to young adulthood: the Bogalusa Heart Study. J Am Diet Assoc 2004 Nov;104(11):1684-91.

35. Black E, Holst C, Astrup A, et al. Diabet Med 2005 Sep;22(9):1199-1205.

36. Prescription for Health [homepage on the Internet]. Aurora (CO): Perscription for Health National Program Office. [updated 2006 Nov 3; cited 2007 Jan 31]. Available from: http://www.prescriptionforhealth.org. 